\title{
On the Processing Feasibility, Microstructure Evolution, and Mechanical Properties of Laser Clad Stellite ${ }^{\circledR} 21$ Alloy
}

\author{
Jeremy H. Rao ${ }^{1,2} \cdot$ Nikki Stanford ${ }^{1}$
}

Submitted: 4 August 2020/in revised form: 6 November 2020/Accepted: 17 November 2020

(C) ASM International 2021

\begin{abstract}
Laser cladding is widely used for feature repair and manufacturing of large structural components. However, due to processing parameters and thus energy densities variation, defects can form in laser clad materials. There is a need to understand the relationship between energy densities and cladding quality. This study therefore investigates the critical parameters in producing structural Stellite ${ }^{\circledR} 21$ (Co-Cr-MoNiC) alloy by laser cladding. Compared with conventional manufacturing, laser clad materials possess ultrafine $\alpha$-Co dendrites and $\sigma-\mathrm{CoCr}$ interdendritic eutectics due to the fast cooling rate. In addition, adjustment of the energy densities can help control defects and improve corrosion resistance. The wear resistance, microhardness, and phase analysis in the laser clad materials are also discussed in this work.
\end{abstract}

Keywords corrosion resistance $\cdot$ defects $\cdot$ laser cladding . mechanical properties $\cdot$ microstructure $\cdot$ stellite $^{\circledR} 21$ alloy

This article is an invited paper selected from abstracts submitted for the 2020 International Thermal Spray Conference, ITSC2020, that was to be held from June 10-12, 2020, in Vienna, Austria. The conference was canceled due to the coronavirus (COVID-19) pandemic. The paper has been expanded from the planned presentation.

Jeremy H. Rao

jeremy.rao@monash.edu

1 Future Industries Institute, University of South Australia, Mawson Lakes, SA 5095, Australia

2 Department of Materials Science and Engineering, Monash University, Clayton, VIC 3800, Australia

\section{Introduction}

As one of the most typical surface modification techniques, laser cladding has been widely used for the repair and build of structural components (Ref 1-3). Due to the fast cooling rate, the solidification scenarios and solid-state transformations are the key controlling factors for the final product performance. Laser cladding is also an effective hard facing method to improve the wear and crack resistance by depositing surface layers of a hard material onto a softer base (Ref 4,5 ). This technology provides possibilities to produce complex alloy and composite coatings with unique properties (Ref 6).

Cobalt-based alloys, also known as stellite alloys, exhibit excellent resistance to mechanical attack and chemical degradation in aggressive environments (Ref 7). They are capable of functioning in high-temperature environments without compromising their high hardness and wear resistance (Ref 7, 8). In particular, Stellite ${ }^{\circledR} 21$ is one of the typical materials used to greatly reduce wear because of its high strength (Ref 9), which also exhibits better erosion-corrosion behaviors than most of the stainless steels (Ref 10). Therefore, Stellite ${ }^{\circledR} 21$ has been used in conventional hardfacing processes to create excellent metallurgical bonded and thick coatings, to make the best of its wear resistance advantages (Ref 11, 12). This includes highly demanding conditions such as for the coating of fast breeder reactors and cutting machine components (Ref 13,14), repairing or adding structural components, such as gear teeth, splines or shaft repair for power generation and pump industries (Ref 13, 14).

Considering the coating quality of the laser clad Stellite ${ }^{\circledR} 21$ deposit, parameter optimisation is of vital importance to help control defects such as pores and cracks initiated (Ref 9). In addition, the fast solidification rate 
during laser cladding introduces a fine network of dendrites and associated undissolved fine carbides in the melt pools of the Co matrix (Ref 6). It has been reported that due to different cooling rates from the top surface to the substrate interface, a graded microstructure is generated, involving gradual transition in the mechanical properties of laser clad Stellite ${ }^{\circledR} 21$ (Ref 13).

This work studies the influence of laser processing parameters and thus energy densities on the underlying physics, and thus metallurgical/mechanical properties of laser clad Stellite ${ }^{\circledR} 21$ coatings. The microstructure analysis, chemical and phase compositions were reported. Additionally, microhardness, as well as resistance to wear and corrosion tests, was evaluated. Bonding between the Stellite ${ }^{\circledR} 21$ deposit and the substrate metal matrix was also investigated in order to build the relationship between the various properties.

\section{Experimental Methods}

\section{Materials and Coating Application}

The material studied was laser clad Stellite ${ }^{\circledR}$ 21. The substrate used for the cladding was a G250 mild steel to offer a good combination of strength and toughness. The chemical compositions of these two materials are shown in Table 1. Powder size and particle distribution are shown in Fig. 1, where the general morphology of Stellite ${ }^{\circledR} 21$ powder has a spherical shape in the range of $-106+53 \mu \mathrm{m}$. The $\mathrm{d}(0.1)$ and $\mathrm{d}(0.9)$ measured using laser diffraction by Mastersizer 2000 (Malvern Panalytical Ltd, UK) were $51.47 \mu \mathrm{m}$ and $103.40 \mu \mathrm{m}$, respectively.

Stellite ${ }^{\circledR} 21$ coatings were prepared by laser cladding technology at LaserBond using a $16 \mathrm{~kW}$ diode laser with the laser beam diameter of $4.8 \mathrm{~mm}$. A Cu powder feeding nozzle was used, and the angle between the nozzle and the specimen was $90^{\circ}$. The steel substrate was preheated at $200{ }^{\circ} \mathrm{C}$. Both helium and argon were used as the carrier gas for the powder and as the shielding gas to protect the melt pools from oxidation, at the same time to balance the cost. Samples $\mathrm{a}$ and $\mathrm{b}$ were produced with double layers while samples $\mathrm{c}$ and $\mathrm{d}$ were fully clad with one layer.

Since the laser heat energy is partially absorbed by the powder and partially by the substrate to cause melting of the feedstock powder, variables known as laser energy densities, including area energy density $E_{a}$ and powder energy density $E_{p}$, have been studied in previous work to evaluate the whole cladding process [15-17]. Volumetric energy density $E_{v}$ was also introduced in this work to investigate the effects of overall energy density on the final properties of laser clad samples. The formula can be expressed as follows:

$E_{a}=P / D v$

$E_{p}=P / F$

$E_{v}=P / D v t$

where $P$ is the laser power $(\mathrm{W}), D$ is the laser beam diameter $(\mathrm{mm}), v$ is the laser scan speed $(\mathrm{mm} / \mathrm{s}), F$ is the powder feed rate $(\mathrm{g} / \mathrm{s})$, and $t$ is layer thickness $(\mathrm{mm})$. The specific energy densities of each laser clad sample are shown in Table 2.

\section{Microstructure Observation}

Metallographic samples were prepared using $\mathrm{SiC}$ papers and finished by polishing with colloidal silica suspension, $0.04 \mu \mathrm{m}$ (OPS). A light microscope (Olympus SC 50) was used to evaluate the microstructure of the tested materials and depths of the clad cross sections. Detailed microstructural characterisation was carried out using a Zeiss Merlin field emission gun (FEG) scanning electron microscopy (SEM) with a $15 \mathrm{kV}$ accelerating voltage and an energy-dispersive $\mathrm{x}$-ray (EDS) detector for semiquantitative indication of the chemical compositions of the test materials.

\section{Microhardness and Wear Resistance Measurement}

Microhardness was measured using a Microindenter Nanovea based on ASTM E92 standard with a load of $3 \mathrm{~N}$. Using the microscope and measuring device, the size of the indentation marks and cracks was automatically measured and calculated. Ten indentations were performed for each sample with one maximum and one minimum value removed. The mean values and standard deviations of the rest eight tests were taken to give an average data point and a corresponding error bar. A through depth microhardness profile was also taken on each sample to establish how the hardness altered with the cladding depth.

Sliding wear tests were performed by a Microtest MT SERIES pin-on-disk tribometer, with a $10 \mathrm{~mm}$ wear diameter using a $6 \mathrm{~mm}$ diameter steel ball at room
Table 1 Chemical composition of Stellite ${ }^{\circledR} 21$ powder and G250 steel (wt.\%)

\begin{tabular}{lllccccccc}
\hline Element & $\mathrm{Co}$ & $\mathrm{Fe}$ & $\mathrm{Cr}$ & $\mathrm{Mo}$ & $\mathrm{Ni}$ & $\mathrm{Mn}$ & $\mathrm{Si}$ & $\mathrm{C}$ & $\mathrm{Cu}$ \\
\hline Stellite $^{\circledR} 21$ & Bal. & $<2.0$ & 27.5 & 5.4 & 2.6 & $\ldots$ & $<2.0$ & 0.25 & $\ldots$ \\
G250 steel & $\ldots$ & Bal. & 0.25 & 0.1 & 0.5 & 1.7 & 0.55 & 0.12 & 0.4 \\
\hline
\end{tabular}


Fig. 1 SEM micrograph showing the particle size and the morphology of Stellite ${ }^{\circledR} 21$ powder and the volume weight percent powder size distribution

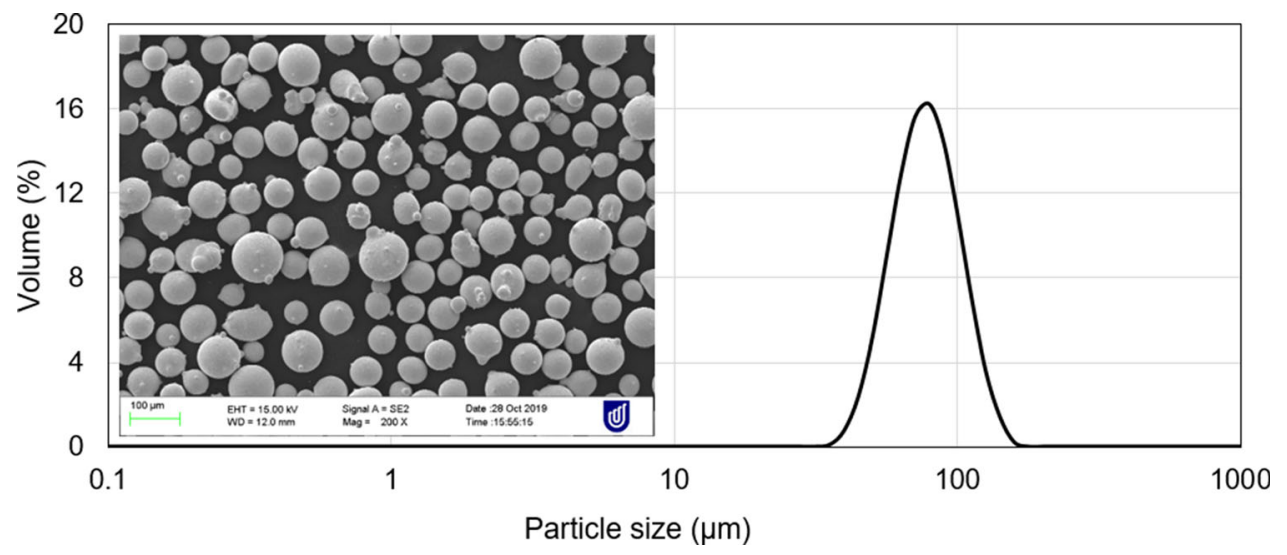

Table 2 Energy densities applied for laser cladding

\begin{tabular}{lcccc}
\hline Sample number & Number of layers & $E_{a}\left(\mathrm{~J} / \mathrm{mm}^{2}\right)$ & $E_{p}(\mathrm{~kJ} / \mathrm{g})$ & $E_{v}\left(\mathrm{~J} / \mathrm{mm}^{3}\right)$ \\
\hline $\mathrm{a}$ & 2 & 33.65 & 5.25 & 18.48 \\
$\mathrm{~b}$ & 2 & 33.65 & 7 & 27.21 \\
$\mathrm{c}$ & 1 & 33.65 & 7 & 34.32 \\
$\mathrm{~d}$ & 1 & 34.38 & 5.28 & 63.66 \\
\hline
\end{tabular}

temperature, impinging vertically on the stellite alloy coating. The sample surfaces were first finely ground and polished to the roughness of less than $0.2 \mu \mathrm{m}$. They were then gravity-loaded with an applied load of $10 \mathrm{~N}$, and the sliding distance was $1000 \mathrm{~m}$ with the rotational speed of $0.1 \mathrm{~m} / \mathrm{s}$. Three tests were conducted per sample. Surface topography was then analyzed by a Laser Confocal Microscope (Olympus Lext OLS5000) with the $20 \times$ lens. Quantitative volume loss was measured based on three test replicates.

\section{Corrosion Tests}

Corrosion tests were performed with WaveNano potentiostats from Pine electrochemistry in a standard 3-electrode electrochemical cell based on ASTM G103(2017)e1 standard. The working electrode is the to-beanalyzed metal coupon, the counter electrode is platinum wire with a surface area of about $4.7 \mathrm{~cm}^{2}$, the reference electrode is silver chloride $(\mathrm{Ag} / \mathrm{AgCl})$ electrode, and the electrolyte is $3.5 \%(\mathrm{w} / \mathrm{v})$ sodium chloride solution with a $\mathrm{pH}$ of 7. The stellite samples were ground with wet $\mathrm{SiC}$ paper of 1200 grit for approximately $10 \mathrm{~min}$ until the surface roughness was $<0.2 \mu \mathrm{m}$. The exposure area of each metal coupon remains $1.6 \mathrm{~cm}^{2}$ throughout all the tests. The open circuit potential (OCP) test was conducted for $1 \mathrm{~h}$. Linear sweep voltammetry was conducted at a scan rate of $15 \mathrm{mV} / \mathrm{min}$ from -300 to $+200 \mathrm{mV}$ (vs. OCP). The polarisation curves (i.e., Tafel plots) and the related parameters such as corrosion current density were deduced from the linear sweep voltammogram. Three repeats of the experiment were performed for each sample.

\section{Results and Discussion}

\section{Microstructure Analysis}

Laser clad structures of stellite coatings are shown in Fig. 2. In each case the coatings were well bonded to the substrate, and the melt pool morphology can be observed. The melt pool boundary areas between the neighboring melt pools are highlighted by the dashed white lines, where different solidification scenarios occur compared with the $\alpha$-Co dendritic areas. With a lower volume energy density and thicker deposition layers in samples $a$ and $b$, the boundary between the coating and the substrate in the sample was a relatively straight line (Fig. 2a and b). Also, larger spherical pores (in Fig. 2a) were more likely to form when a low energy density was applied in sample a (Table 2). This could be due to the insufficient melting of Stellite $^{\circledR} 21$ matrix or oxygen gas porosity due to the gas atomised powder, observed in previous work for additively manufactured materials as well [17-19].

Furthermore, with an increased volumetric energy density (Fig. 2d), a much denser microstructure was formed in sample d, with smaller pore size and no cracks observed. In addition, to clarify the microstructural difference from the parameter optimisation, samples $\mathrm{c}$ and $\mathrm{d}$ were also observed at a much higher magnification. Apart from the obvious crack in sample c (Fig. 2e), similar morphology of 
Fig. 2 (a)-(d) Macrostructure of laser clad Stellite ${ }^{\circledR} 21$ coating on G250 stainless steel, the specimen designation and applied energy densities correspond to sample a, b, c, d shown in Table 2, respectively; backscattered electrons (BSE) images for (e) sample $c$ and (f) sample d. The melt pool boundaries and defects, including pores and cracks, are marked by the dashed and solid lines, respectively (a)

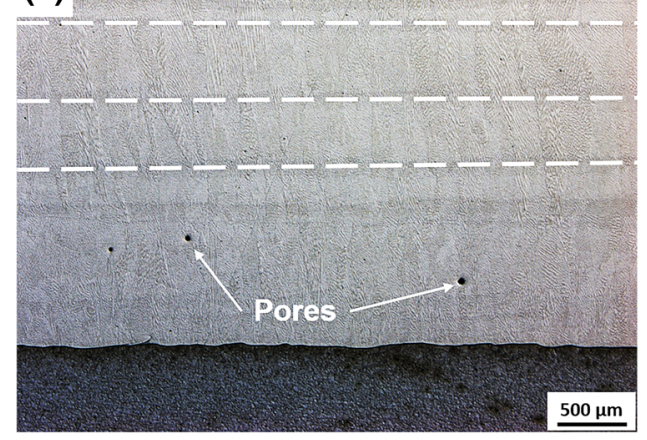

(b)
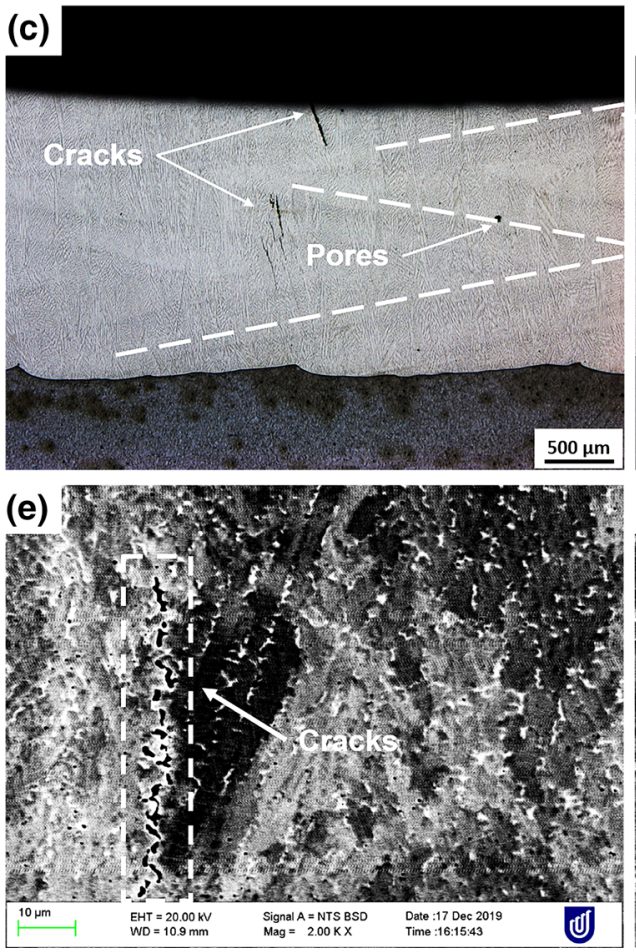
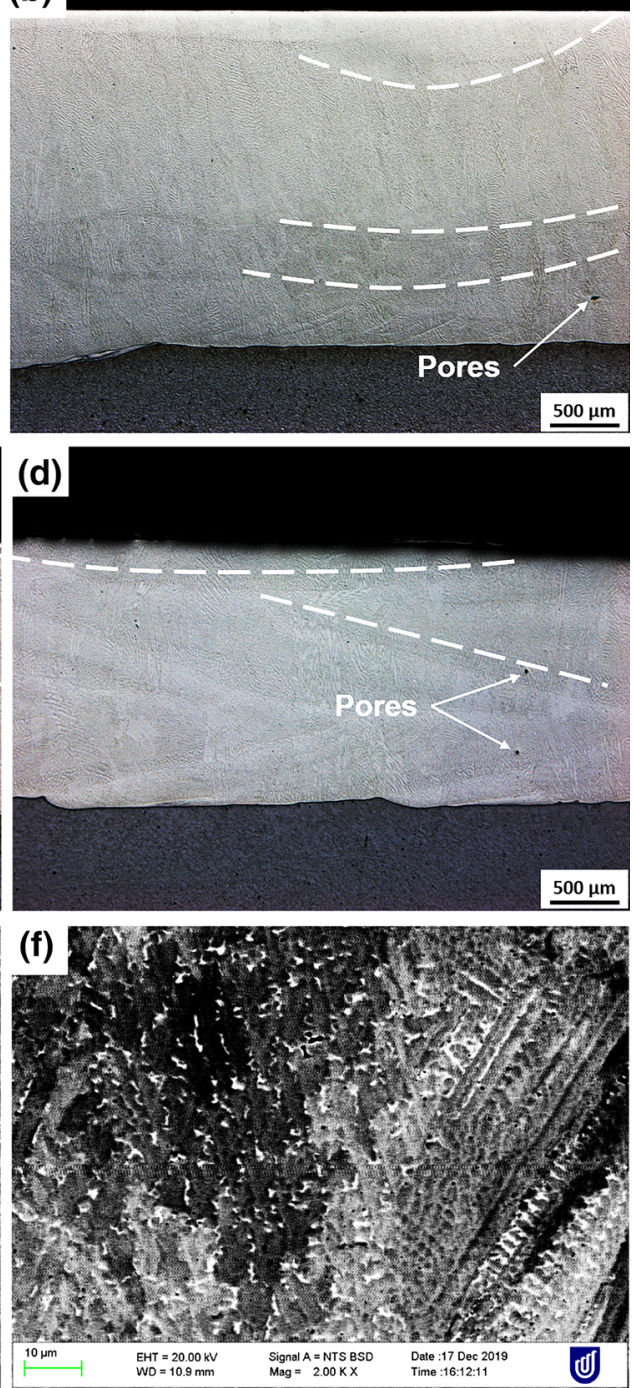

the dendrites is determined in these two samples. For instance, ultrafine $\alpha$-Co dendrites and $\sigma-\mathrm{CoCr}$ interdendritic eutectics are observed as the dark areas and white secondary phases in both samples $\mathrm{c}$ and $\mathrm{d}$, respectively (Fig. 2e and $\mathrm{f}$ ). Therefore, the formation mechanisms of cracks in the Co matrix is not closely correlated to the energy input for each sample.

With a typical dendritic type hypoeutectic microstructure, Stellite ${ }^{\circledR} 21$ samples contain primary Co-rich dendrites, surrounded by $\mathrm{Cr}$-rich eutectics in a supersaturated solid solution matrix (Fig. 3). A gradient microstructure is formed toward the substrate boundary (Fig. 3a). On one hand, the coarser dendrites are mainly because of the deceased solidification rate when approaching the preheated substrate and getting away from the cooling atmosphere. On the other hand, partial melting of the substrate not only created a better metallurgical joining with coatings, but also promoted the $\mathrm{Fe}$ diffusion in the stellite matrix of less than 5\% (Fig. 3b). Since no other element migration at the interface was clearly observed, only $\mathrm{Fe}$ is shown here. Therefore, non-uniformity of the microstructure around metal bonding areas due to the Fe element migration from the base material would not have a significant impact on the shape of dendrites.

A characteristic feature of dendritic micro-segregation due to a diversity of cooling rates on the cross section can be observed (Fig. 4a). At higher magnifications (Fig. 4b), few different regions can be determined around the melt pool areas according to the eutectic morphology, which have been studied in the previous work [17]: (c) melt pool core, (d) melt pool border, (e) vertical dendritic region. Melt pool cores, with the highest cooling rates, represent regions with finest and isolated primary Co dendrites and $\mathrm{Cr}$ eutectics, while melt pool borders represent the coarse and fibrous ones. In particular, vertical dendritic regions possess a special morphology with the Co dendrites 
Fig. 3 (a) OM image of sample $\mathrm{d}$ showing the gradient microstructure toward the stellite-steel interface as the solid arrow points; (b) SEM image showing the highlighted area at a higher magnification, with EDS mapping image showing the Fe element migration around the interface areas
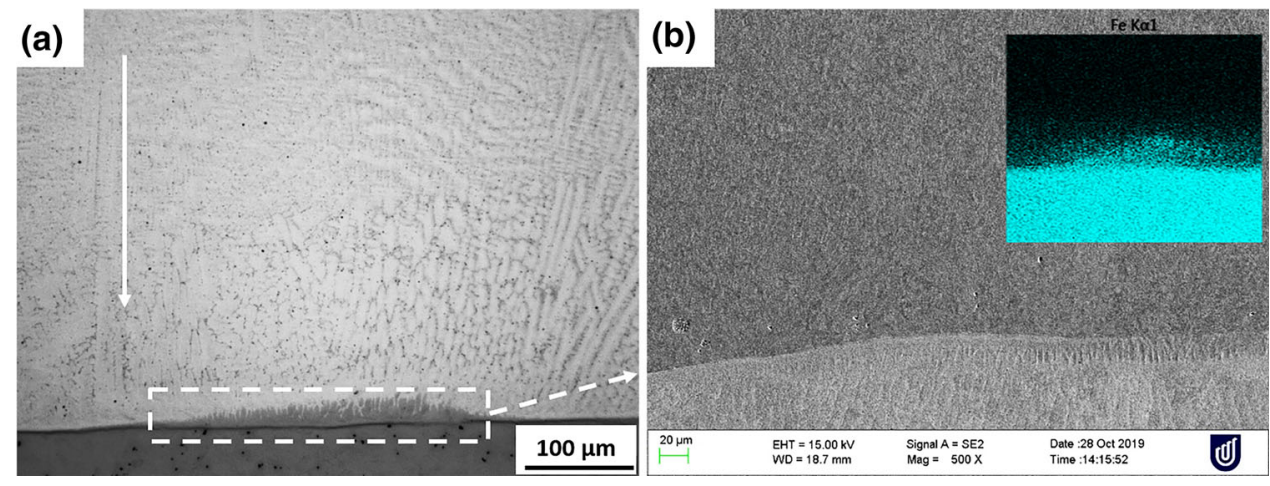
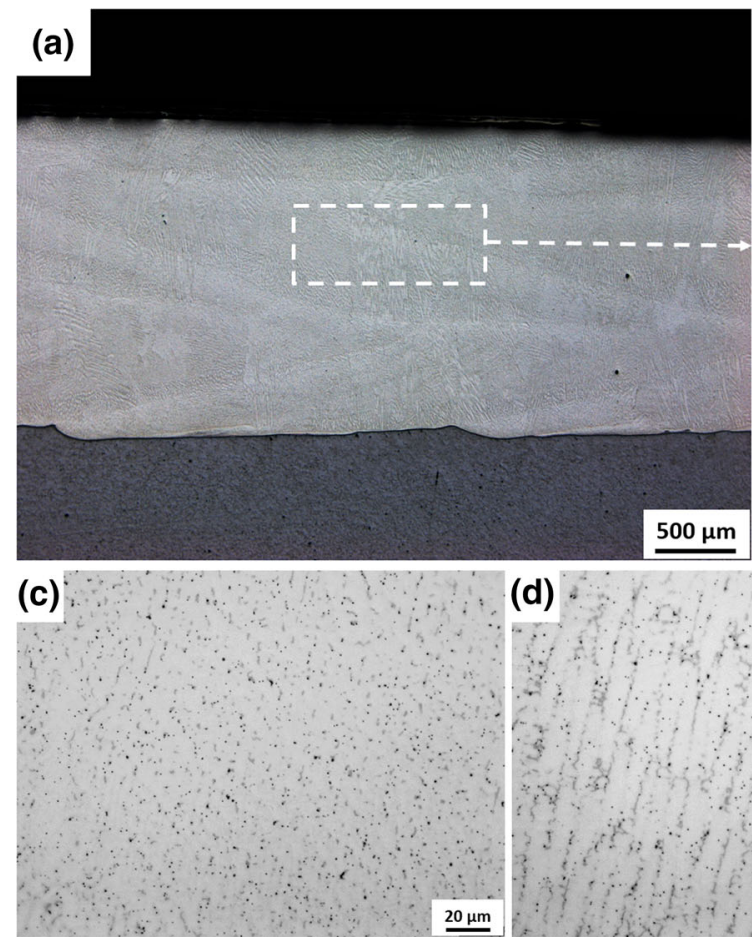
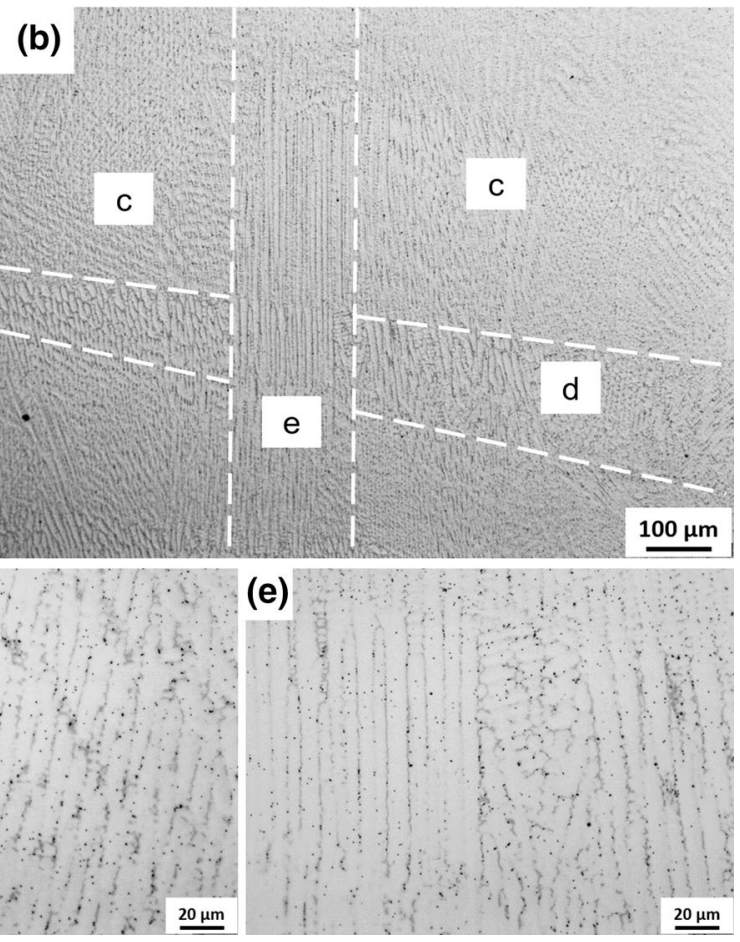

Fig. 4 (a) OM microstructure of sample d showing (b) the arrowed area at higher magnification with three different regions distinguished: (c) melt pool core, (d) melt pool border, (e) vertical dendritic region (VDR)

growing vertically toward the interface. Apart from the lowest defects level, the ultrafine microstructure in sample $\mathrm{d}$ also contributed to the improved properties. Therefore, future work is proposed to determine the further influence of laser parameters on the microstructural evolution and thus the properties of laser clad Stellite ${ }^{\circledR} 21$.

\section{Hardness Analysis}

The average hardness for each sample was measured on the sample surface as shown in Fig. 5(a), and the error bars represent the scatter between eight replicates. The hardness variation is not likely to be resulted from the change in the energy densities (Table 2). For instance, although certain levels of porosity and cracking were created for samples a and c, their corresponding hardness is still higher than sample b with the least defects observed.

Through thickness measurements were also made along a straight line at the cross section, which starts from $100 \mu \mathrm{m}$ below the sample surface (Fig. 5b). Although no significant difference in the microhardness was found between the zone close to the cladding surface and the one away from it, the through thickness hardness in Fig. 3(b) corresponds to the surface hardness values in Fig. 3(a) pretty well.

\section{Wear Resistance}

During pin-on-disk tests, the changes in the friction coefficient were recorded and analyzed. For instance, three 


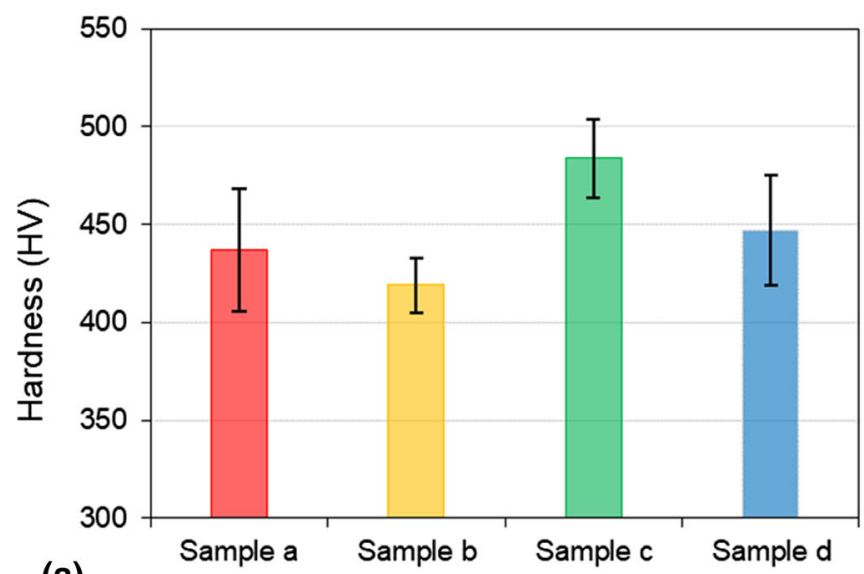

(a)

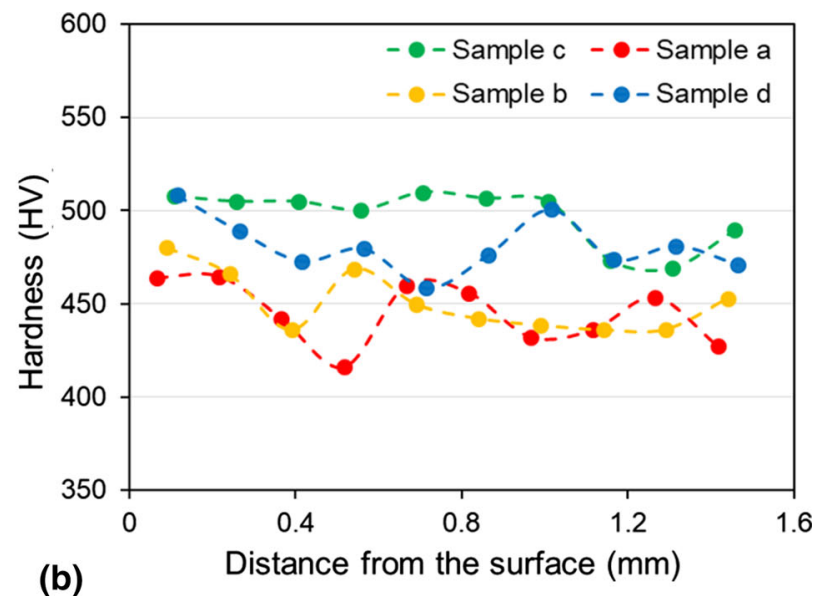

Fig. 5 (a) Average microhardness for each laser clad sample; (b) microhardness profiles of each material against the surface depth

(a)

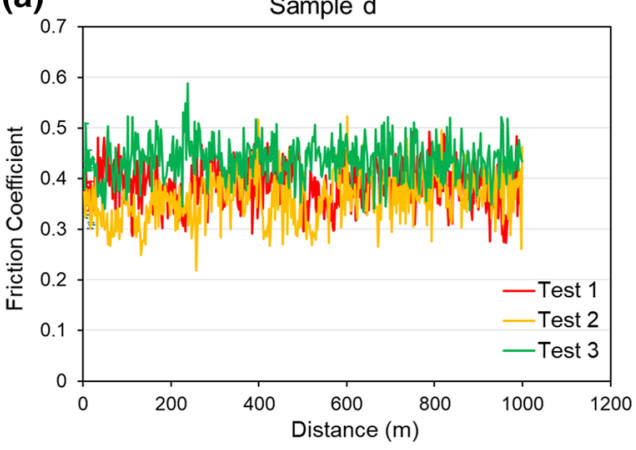

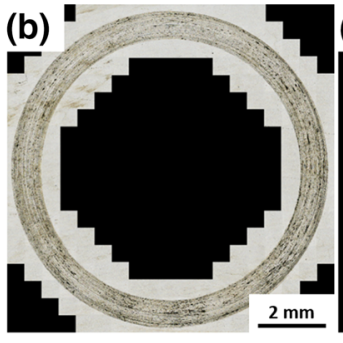

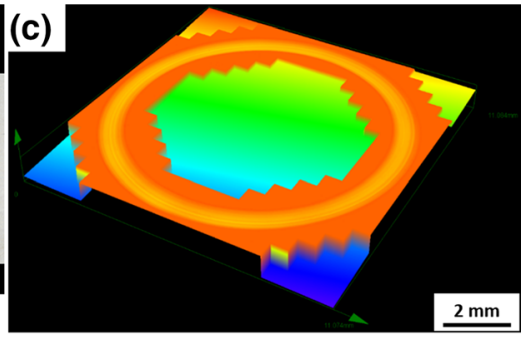

Fig. 6 (a) The friction coefficient profile of pin-on-disk tests for sample d, (b) representative 2D view of pin-on-disk wear scars, (c) representative $3 \mathrm{D}$ view of wear scars

friction profiles for sample $d$ are shown in Fig. 6(a). The wear scar depth profiles were measured to assess the total volume loss. An indicative wear scar is shown in Fig. 4(b) and (c) as 2D and 3D views, respectively. The volume loss was determined within the superimposed orange rings, representing the zones directly underneath the stainless balls used during pin-on-disk tests (Fig. 6).

All traces displayed a steady friction coefficient during the $1000 \mathrm{~m}$ wear distance, no significant wear was observed, and the average coefficient of friction for each sample was calculated and is shown in Fig. 7, which agrees well with the previous work [4, 20, 21]. For the volume loss, sample d possesses the lowest value, while samples a and $\mathrm{c}$ the highest, although the difference is not practically significant.

The relationships of volume energy density $\left(E_{v}\right)$ versus wear resistance are plotted in Fig. 8. At a relatively lower energy density range, its influence on the wear resistance properties is limited. However, as $E_{v}$ largely increases in sample d, the volume loss becomes the lowest, indicating the best wear resistance. This is likely to be correlated to

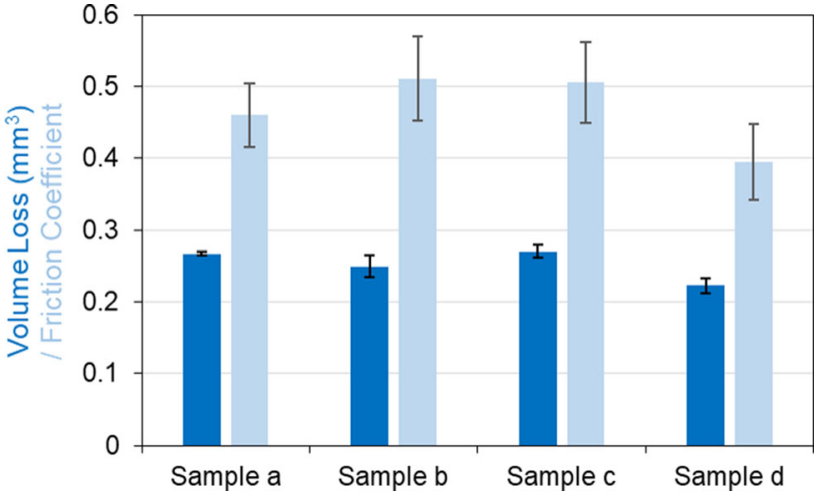

Fig. 7 Average friction coefficient for each laser clad sample

the nearly dense microstructure generated in sample $d$, as the influence of the defects is almost eliminated in this case. In addition, based on previous work, friction coefficients are not directly correlated to volume loss [4, 20, 21]. They may be affected by various factors in a wear process such as material defects and testing conditions. 


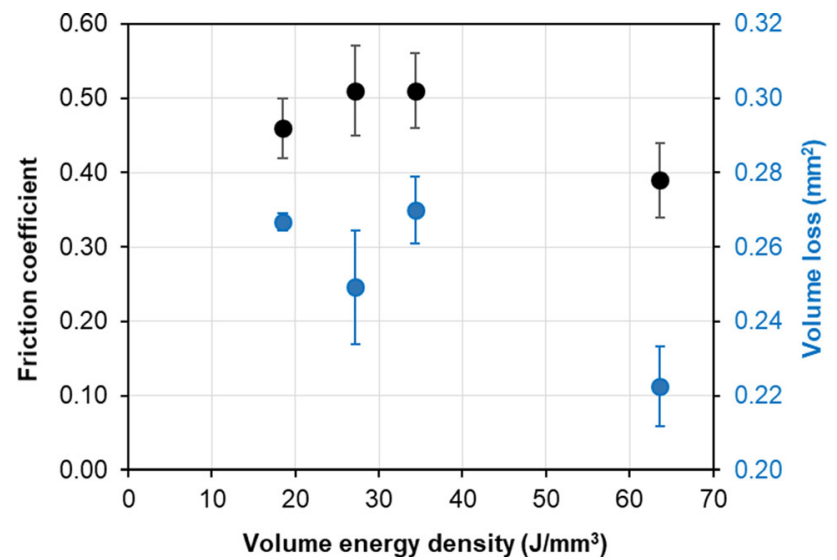

Fig. 8 The relationship between volume energy density and wear resistance

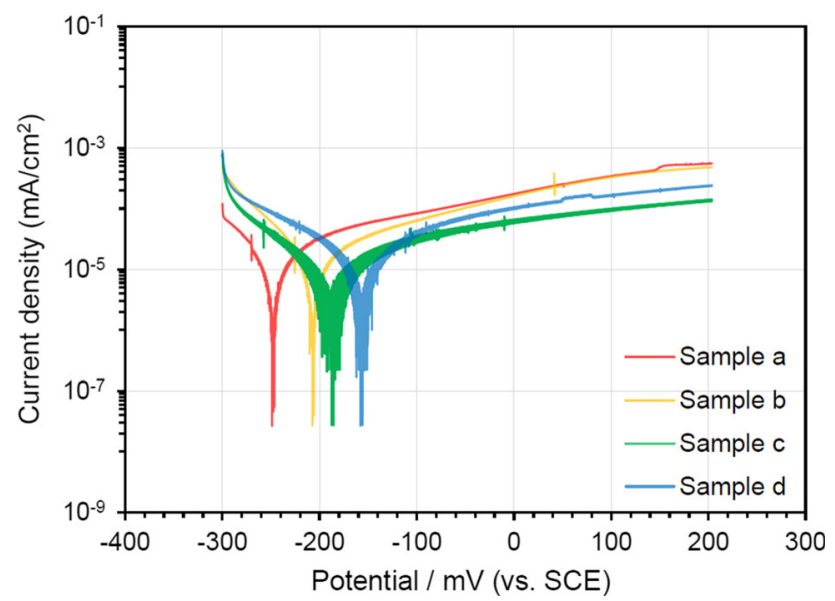

Fig. 9 Corrosion resistance of different laser clad Stellite ${ }^{\circledR} 21$ samples

\section{Corrosion Resistance}

The corrosion resistance behaviors of the stellite samples were investigated in $3.5 \%(\mathrm{w} / \mathrm{v})$ sodium chloride solution at room temperature with a potentiodynamic polarisation method. The polarisation curves for each sample are shown in Fig. 9. For samples $\mathrm{c}$ and d, a spontaneously passivetranspassive behavior can be clearly observed. The noise or serration in the passive region of the curves suggests an unstable passivity of the sample, i.e., the passive film on the surface of samples undergoes a cycle of localised breakdown and immediate re-passivation. This is also suggested by the current increase for all samples. In comparison, less passivation effect was observed on the polarisation curves of samples a and $b$, as the current density increases more steadily with the increase in the potential.
Table 3 Corrosion parameters determined based on potentiodynamic curves

\begin{tabular}{lcccc}
\hline $\begin{array}{l}\text { Corrosion } \\
\text { parameters }\end{array}$ & Sample a & Sample b & Sample c & Sample d \\
\hline $\begin{array}{l}I_{\text {corr }}(\mathrm{mA} / \\
\mathrm{cm} 2)\end{array}$ & $1.68 \mathrm{E}-06$ & $1.60 \mathrm{E}-06$ & $2.07 \mathrm{E}-06$ & $2.12 \mathrm{E}-06$ \\
$E_{\text {corr }}(\mathrm{mV})$ & -248.88 & -207.35 & -191.35 & -158.40 \\
\hline
\end{tabular}

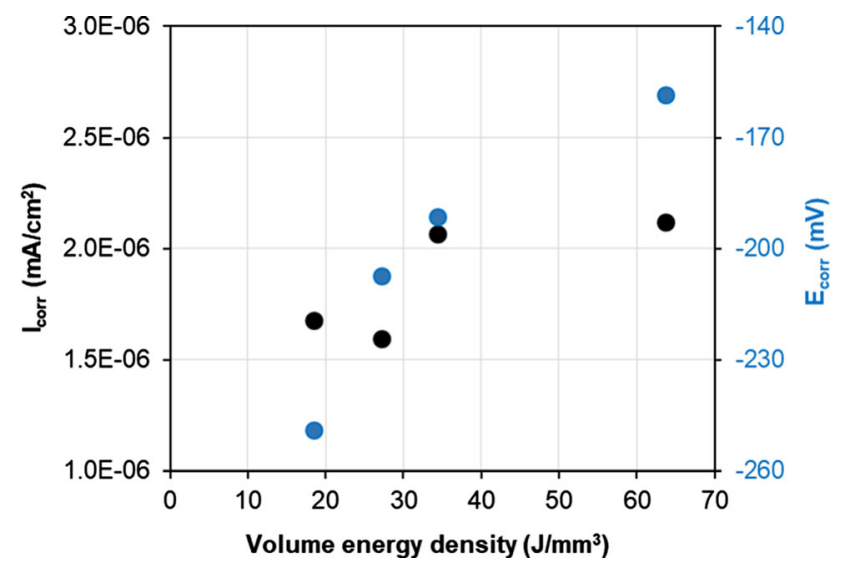

Fig. 10 The relationship between volume energy density and corrosion resistance

The key corrosion parameters, deduced from the curves by Tafel extrapolation method, are listed in Table 3. A general trend can be observed that from sample $d$ to $a$, the corrosion potential $\left(E_{\text {corr }}\right)$ of the steel sample goes to more negative value, indicating a rise in the rate of corrosion [22].

The relationships of volume energy density $\left(E_{v}\right)$ versus corrosion resistance are plotted in Fig. 10. The influence of $E_{v}$ on the corrosion current density $\left(I_{\text {corr }}\right)$ is much less compared with that on the corrosion potential $\left(E_{\text {corr }}\right)$. With the increase in $E_{v}$, corrosion potentials were found to increase significantly. For sample d with the highest $E_{\text {corr }}$ of $-158 \mathrm{~V}$, its corrosion resistance is the highest. For sample a, however, its lowest $E_{\text {corr }}$ indicates a lower ability to resist the onset of corrosion. In this regard, sample d, with the lowest defect levels obtained so far, possesses the best overall properties.

\section{Conclusions}

1. The partial laser heat absorption by the powder and the substrate leads to localised heat flow in the melt pools, generating several different regions with varied morphologies of Cr-rich eutectic cells surrounding supersaturated Co-rich dendrites around melt pool areas. 
2. The microhardness is not related to the various energy densities applied, and thus not affected by defects levels as well. A high hardness uniformity throughout the cladding depth can also be observed.

3. Although an ultrafine gradient microstructure is obtained in all the as-fabricated Stellite ${ }^{\circledR} 21$ samples because of the fast cooling rates, their porosity formation mechanisms still vary from each other.

4. A novel variable, volumetric energy density $\left(E_{v}\right)$, was introduced in this work to take all the key parameters into account and to help correlate the relationship between final properties of laser clad samples. This cannot be easily obtained by conventionally derived values such as area energy density $\left(E_{a}\right)$ and powder energy density $\left(E_{p}\right)$.

5. An increased $E_{v}$ witnesses the rise in the wear resistance and an enhanced corrosion resistance, providing an approach to improve future overall properties of laser clad materials.

Acknowledgements This work was supported by Australia Research Council (ARC) "Industrial Transformation Training Centre (ITTC) in Surface Engineering for Advanced Materials (SEAM)" under Grant [IC180100005]. The authors acknowledge the facilities, scientific, and technical assistance of Future Industries Institute (FII), Australian National Fabrication Facility (ANFF)-SA Node, and Microscopy Australia at the University of South Australia, the State and Federal Governments, LaserBond Ltd. The continued support of Prof Chris Berndt and Prof Emily Hilder is also gratefully acknowledged.

\section{References}

1. N. Ahmed, Direct Metal Fabrication in Rapid PROTOTYPING: a Review, J. Manuf. Process., 2019, 42, p 167-191

2. S.M. Thompson, L. Bian, N. Shamsaei, and A. Yadollahi, An Overview of Direct Laser Deposition for Additive Manufacturing; Part I: Transport Phenomena, Modeling and Diagnostics, Addit. Manuf., 2015, 8, p 36-62

3. Y. Hu and W. Cong, A Review on Laser Deposition-Additive Manufacturing of Ceramics and Ceramic Reinforced Metal Matrix Composites, Ceram. Int., 2018, 44(17), p 20599-20612

4. J.-W. Seo, J.C. Kim, S.-J. Kwon, and H.-K. Jun, Effects of Laser Cladding for Repairing and Improving Wear of Rails, Int. J. Precis. Eng. Manuf., 2019, 20, p 1207-1217

5. A.S.C.M. D'Oliveira, P.S.C.P. da Silva, and R.M.C. Vilar, Microstructural Features of Consecutive Layers of Stellite 6 Deposited by Laser Cladding, Surf. Coat. Technol., 2002, 153(2), p 203-209

6. G. Xu, M. Kutsuna, Z. Liu, and L. Sun, Characteristic Behaviours of Clad Layer by a Multi-layer Laser Cladding with Powder Mixture of Stellite-6 and Tungsten Carbide, Surf. Coat. Technol., 2006, 201(6), p 3385-3392

7. I. Radu and D.Y. Li, The Wear performance of Yttrium-Modified Stellite 712 at Elevated Temperatures, Tribol. Int., 2007, 40(2), p 254-265
8. A. Yaedu and A. Doliveira, Cobalt Based Alloy PTA Hardfacing on Different Substrate Steels, Mater. Sci. Technol., 2005, 21(4), p 459-466

9. Y. Zhu, Y. Yang, X. Mu, W. Wang, Z. Yao, and H. Yang, Study on Wear and RCF Performance of Repaired Damage Railway Wheels: Assessing Laser Cladding to Repair Local Defects on Wheels, Wear, 2019, 430-431, p 126-136

10. F. Brownlie, T. Hodgkiess, A. Pearson, and A. Galloway. In Corrosive wear behaviour of various stainless steel alloys and a Stellite 6 weld cladding, 17th Nordic Symposium on Tribology, 2016; pp. 1-12.

11. G.P. Rajeev, M. Kamaraj, and S.R. Bakshi, Hardfacing of AISI, H13 Tool Steel with Stellite 21 Alloy using Cold Metal Transfer Welding Process, Surface Coat Technol, 2017, 326, p 63-71

12. G. Rajeev, M. Kamaraj, and S.R. Bakshi, Comparison of Microstructure, Dilution and Wear Behavior of Stellite 21 Hardfacing on H13 Steel Using Cold Metal Transfer and Plasma Transferred Arc Welding Processes, Surf. Coat. Technol., 2019, 375, p 383-394

13. P. Ganesh, A. Moitra, P. Tiwari, S. Sathyanarayanan, H. Kumar, S.K. Rai, R. Kaul, C.P. Paul, R.C. Prasad, and L.M. Kukreja, Fracture Behavior of Laser-Clad Joint of Stellite 21 on AISI, 316L Stainless Steel, Mater. Sci. Eng. A, 2010, 527(16), p 37483756

14. F. Brownlie, T. Hodgkiess, A. Pearson, and A.M. Galloway, Effect of Nitriding on the Corrosive Wear Performance of a Single and Double Layer Stellite 6 Weld Cladding, Wear, 2017, 376-377, p 1279-1285

15. O. Devojno, E. Feldshtein, M. Kardapolava, and N. Lutsko, On the Formation Features, Structure, Microhardness and Tribological Behavior of Single Tracks and Coating Layers Formed by Laser Cladding of Al-Fe Powder Bronze, Surf. Coat. Technol., 2019, 358, p 195-206

16. D.P. Karmakar, M. Gopinath, and A.K. Nath, Effect of Tempering on Laser Remelted AISI, H13 Tool Steel, Surf. Coat. Technol., 2019, 361, p 136-149

17. H. Rao, S. Giet, K. Yang, X. Wu, and C.H.J. Davies, The Influence of Processing Parameters on Aluminium Alloy A357 Manufactured by Selective Laser Melting, Mater. Des., 2016, 109, p 334-346

18. K.V. Yang, P. Rometsch, T. Jarvis, J. Rao, S. Cao, C. Davies, and X. Wu, Porosity Formation Mechanisms and Fatigue Response in Al-Si-Mg Alloys Made by Selective Laser Melting, Mater. Sci. Eng. A, 2018, 712, p 166-174

19. J.H. Rao, Y. Zhang, A. Huang, X. Wu, and K. Zhang, Improving Fatigue Performances of Selective Laser Melted Al-7Si-0.6 Mg Alloy via Defects Control, Int. J. Fatigue, 2019, 129, p 105215

20. M.X. Yao, J.B.C. Wu, and Y. Xie, Wear, Corrosion and Cracking Resistance of Some W- or Mo-Containing Stellite Hardfacing Alloys, Mater. Sci. Eng. A, 2005, 407(1), p 234-244

21. R. Liu, J.H. Yao, Q.L. Zhang, M.X. Yao, and R. Collier, Sliding Wear and Solid-Particle Erosion Resistance of a Novel HighTungsten Stellite Alloy, Wear, 2015, 322-323, p 41-50

22. D. Bartkowski, A. Młynarczak, A. Piasecki, B. Dudziak, M. Gościański, and A. Bartkowska, Microstructure, Microhardness and Corrosion Resistance of Stellite-6 Coatings Reinforced with WC Particles Using Laser Cladding, Opt. Laser Technol., 2015, 68, p 191-201

Publisher's Note Springer Nature remains neutral with regard to jurisdictional claims in published maps and institutional affiliations. 